\title{
BMJ Open Accuracy of the days' supply and the number of refills allowed recorded in Québec prescription claims databases for inhaled corticosteroids
}

\author{
Lucie Blais, ${ }^{1,2,3}$ Anne Vilain, ${ }^{1}$ Fatima-Zohra Kettani, ${ }^{1,2}$ Amélie Forget, ${ }^{1,2}$ \\ Geneviève Lalonde, ${ }^{1}$ Marie-France Beauchesne, ${ }^{1,3,4,5}$ Francine M Ducharme, ${ }^{6,7}$ \\ Catherine Lemière ${ }^{1,2}$
}

To cite: Blais L, Vilain A, Kettani F-Z, et al. Accuracy of the days' supply and the number of refills allowed recorded in Québec prescription claims databases for inhaled corticosteroids. BMJ Open 2014;4:e005903. doi:10.1136/bmjopen-2014005903

- Prepublication history and additional material is available. To view please visit the journal (http://dx.doi.org/ 10.1136/bmjopen-2014005903).

Received 11 June 2014 Revised 20 August 2014 Accepted 1 September 2014

CrossMark

For numbered affiliations see end of article.

Correspondence to

Dr Lucie Blais;

lucie.blais@umontreal.ca

\section{ABSTRACT}

Objectives and hypotheses: Adherence to inhaled corticosteroids (ICS) is a major issue in asthma. This study aimed to estimate the accuracy of the days' supply and number of refills allowed, variables recorded in Québec claims databases and used to estimate adherence, and to develop correction factors, if required. We hypothesised that the accuracy of the days' supply for ICS would be low whereas the accuracy of the number of refills allowed would be high.

Setting: 40 community pharmacies in Québec (Canada) and a medication registry.

Participants: We collected data for 1108 ICS original prescriptions stored in the 40 pharmacies (sample 1), and we obtained a second sample of 2676 ICS prescriptions selected from reMed, a medication registry (sample 2).

Primary and secondary outcomes: We estimated the concordance of the days' supply and number of refills between Québec claims databases and the original prescription from sample 1. We developed a correction factor for the days' supply in sample 1 and validated it in sample 2 . Analyses were stratified by age: $0-11$ and 12-64 years.

Results: In sample 1, the concordance for the days' supply was $39.6 \%(95 \% \mathrm{Cl} 37.6 \%$ to $41.6 \%)$ in those aged $0-11$ years and $56 \%(54.9 \%$ to $57.2 \%$ ) in those aged 12-64 years. The concordance increased to $59.4 \%$ $(58.2 \%$ to $60.5 \%)$ in those aged $0-11$ years and $74.2 \%$ $(73.5 \%$ to $74.9 \%)$ in those aged $12-64$ years after applying the correction factors in sample 2. The concordance for the refills allowed was $92.1 \%$ ( $91 \%$ to $93.1 \%$ ) in those aged $0-11$ years and $93.1 \%(92.5 \%$ to $93.7 \%$ ) in those aged 12-64 years in sample 1.

Conclusions: The accuracy of the days' supply was moderate among those aged $0-11$ years and substantial among those aged 12-64 years after applying the correction factors. The accuracy of the number of refills was almost perfect in both groups.

\section{INTRODUCTION}

Prescription claims databases are important sources of information on medications dispensed in community pharmacies, and are increasingly being used to estimate the level of

\section{Strengths and limitations of this study}

- This validation study used a representative large population-based sample of inhaled corticosteroid (ICS) prescriptions covering patients up to 65 years of age.

- Correction factors for the days' supply of ICS used in the assessment of medication adherence, were developed and validated in an independent second large sample.

- This study is the first one to evaluate the accuracy of the number of refills allowed, also used in adherence calculation.

- Patients aged $>65$ years were not considered since the prescription drug database used for this study does not include them.

- The clinical indication for the ICS prescriptions was unknown.

adherence to medications prescribed for the treatment of chronic diseases. ${ }^{1-7}$ The days' supply, defined as the number of days of supply of the medication provided to the patient for a filled prescription and recorded in prescription claims databases, is used to calculate several measures of adherence such as the medication possession ratio, ${ }^{89}$ the proportion of days covered, ${ }^{89}$ and the proportion of prescribed days covered. ${ }^{10}$ The latter is an adherence measure that we recently developed and that accounts for variations in the way the medication is prescribed via the number of refills allowed, ${ }^{10}$ which corresponds to a specific number or time frame indicated by the prescriber allowing the patient to obtain more of the same medication without getting a new prescription from the doctor.

Treatment adherence is an issue for the majority of chronic diseases, but is dramatically low for inhaled corticosteroids (ICS), the cornerstone therapy in asthma. ${ }^{1-3} 51011$ The accuracy of the days' supply data recorded in 
prescription claims databases may be worst for inhaled medications than for other medications. Indeed, these medications are commercialised in canisters containing a fixed number of doses, meaning that the lifespan of the canister varies according to the dosage prescribed, and that the days' supply has to be calculated by the pharmacist. Moreover, the duration of the treatment prescribed by the physician (and written on the original prescription sheet) may be shorter than the lifespan of the canister at the prescribed dosage, leaving pharmacists facing a dilemma as to what to record in the pharmacy electronic record (PER). As an example, let's assume a fluticasone metered-dose inhaler containing 120 puffs prescribed two puffs twice daily for 15 days. In this case, the pharmacist may record 15 days in the PER, corresponding to the duration of the prescribed treatment, or 30 days corresponding to the number of days the inhaler would last at the prescribed dosage (ie, 120 puffs divided by 4 puffs per day). On the contrary, the data on the number of refills allowed recorded in the PER is expected to have a good accuracy, since the pharmacist has only to record the value stated on the original prescription, without any calculation.

This being said, the information regarding the accuracy of the days' supply for respiratory medications is very limited. To the best of our knowledge, we found only two studies that found concordance levels of $34.6 \%{ }^{12}$ and $18.1 \%,{ }^{13}$ respectively, for respiratory drugs between the days' supply recorded in claims databases and the original prescription. Regarding the number of refills allowed, we found no study that evaluated its accuracy.

Therefore, the primary objective of this study was to evaluate the accuracy of the days' supply and number of refills allowed recorded in Québec prescription claims databases for ICS, the cornerstone therapy for asthma, using the original prescription stored at the pharmacy as the gold standard. Secondarily, we aimed to develop and validate appropriate correction factors for the days' supply and the number of refills allowed, if required.

\section{METHODS}

The present study was conducted in three steps: (1) assessment of the concordance of the days' supply and number of refills allowed recorded in Québec prescription claims databases for ICS using a sample of original written prescriptions from community pharmacies (sample 1) as the gold standard; (2) development of correction factors for the days' supply or the number of refills allowed, if required, from sample 1; (3) validation of the developed correction factor(s) in another sample of ICS prescriptions (sample 2) selected from reMed, a medication registry.

\section{Accuracy assessment}

\section{Source of data and gold standard}

The accuracy of the days' supply and the number of refills allowed recorded in Québec prescription claims databases was assessed using the original prescriptions stored in community pharmacies as the gold standard. The original prescription usually includes the name of the medication, the number of days of treatment prescribed, the dosage (ie, the number of puffs of ICS prescribed per day and the number of $\mu \mathrm{g}$ per puff) and the number of refills allowed or the duration of validity $(\mathrm{eg}$, 1 year) of the prescription (refills-Rx), among other information. As usually performed by pharmacists, we recorded Refills-Rx as 99 if the physician specified the duration of validity of the prescription instead of the number of refills allowed on the original prescription. Using the dosage and the canister size of ICS prescribed, we calculated the days' supply (days-supply-Rx), that is, the number of days the dispensed inhaler will last at the prescribed daily dose. When the dosage was variable (as needed/step-up or step-down therapy/asthma action plans), we considered the maximum number of puffs of ICS prescribed per day to calculate the days-supply-Rx.

Prescription claims data were retrieved from the PER, which includes information on medications dispensed to patients in the community. Data recorded in the PER are electronically transferred to the RAMQ public prescription claims database and to the claims databases of private insurance companies for reimbursement purposes. Among other variables, the PER includes the days' supply (days-supply-PER) and the number of refills allowed (refills-PER) as recorded by the pharmacist. Refills-PER is recorded at zero if no refills are allowed or at 99 if the prescription specifies a duration of validity instead of a number of refills allowed. In the latter case, the pharmacist will also record the date corresponding to the end of the prescription period in the PER. It is worth noting that the dosage cannot be obtained from the RAMQ prescription claims database, which means it is necessary to rely on the variable days-supply-PER for days' supply and adherence assessment.

\section{Participant selection and data collection for sample 1}

We first selected a representative sample, stratified by age and drug insurance type, of 1200 ICS prescriptions (beclomethasone, budesonide, ciclesonide, fluticasone, budesonide/formoterol, fluticasone/salmeterol) dispensed to patients across 40 pharmacies in Québec between January 2009 and March 2012. We chose to select the pharmacies from the nine most populated administrative regions in Québec based on the complete list of pharmacies obtained from the Ordre des pharmaciens du Québec. We determined the number of pharmacies to be included in proportion to the population density of each region. Then for each region-specific list, we applied the systematic sampling method to select the pharmacies, with a random start and where the sampling interval (the 'skip') corresponds to the total number of pharmacies in each region divided by the number of pharmacies to be included. If the selected pharmacy refused to participate, we asked the next pharmacy on the region-specific list to participate. 
Within each pharmacy, a technician or a pharmacist accessed the PER and provided a list of all patients who filled a new ICS prescription up to 26 months before data collection and selected 30 patients, with 10 aged $<18$ years, 10 aged $18-44$ years and 10 aged $45-65$ years using the systematic sampling method. Half of the patients in each group were to be insured by the RAMQ drug insurance plan and half by private drug insurance plans. The original prescription for the ICS was retrieved for each patient.

Data collection was performed between March 2011 and March 2012. With the help of the pharmacy's technician, a research assistant collected the necessary information from the PER and the original prescriptions stored at the pharmacy. Further details on the variables collected and the eligibility criteria for the prescriptions are summarised in the online supplementary material. The participating pharmacists were given financial compensation $(\$ 75)$ for their time taken to participate in this study.

\section{Statistical analyses performed on sample 1}

We estimated the distributions of patients' and ICS characteristics, days-supply-PER, days-supply-Rx, refillsPER and refills-Rx in sample 1 . We then calculated the exact concordance and 95\% CI between days-supply-PER and days-supply-Rx for all ICS combined and for specific ICS product and canister size (ie, number of puffs per canister). We also calculated the exact concordance and 95\% CI between refills-PER and refills-Rx. Although the $\kappa$ statistic was not the measure of concordance used in this study, we based our interpretation of the concordance findings on the classification system proposed by Landis and Koch for this statistic $(<0$ : no agreement, 0 0.20 : poor agreement, $0.21-0.40$ : fair agreement, $0.41-$ 0.60 : moderate agreement, $0.61-0.80$ : substantial agreement, 0.81-1.00: almost perfect agreement) ${ }^{14}$

All analyses were stratified by age: $0-11$ years and $12-$ 64 years. This age stratification was chosen a posteriori based on the age groups described in the monographs for most ICS. ${ }^{15}$

\section{Development and validation of correction factors}

We aimed to develop correction factors if the concordance for the days' supply or the number of refills allowed would be found lower than $80 \%$ (arbitrary threshold based on the Landis and Koch statistic). We planned to develop correction factors based on data observed from the original prescriptions in sample 1, that is, empirically-based correction factors. The details of the correction factors are presented in the results section. It was also planned to recalculate the concordance after applying the correction factors in sample 1 .

\section{Assessment of the validity of the correction factors} in a second sample

Given the fact that it was necessary to develop a correction factor for the days-supply-PER, we aimed at validating it in another independent sample (sample 2). To do so, we used reMed which is an ongoing researchbased computerised registry that stores data related to prescribed medications for a sample of 28510 Québec residents who are $<65$ years old and covered by a private drug insurance plan. reMed contains similar information as the one found in the RAMQ public prescription claims database, that is, days-supply-PER and refills-PER, with the addition of the dosage. The days-supply-Rx calculated from the dosage recorded in reMed was considered the gold standard in this sample.

From reMed, we selected all new ICS prescriptions (beclomethasone, budesonide, ciclesonide, fluticasone, mometasone, budesonide/formoterol, fluticasone/salmeterol, mometasone/formoterol) filled between January 2009 and November 2013 by patients aged $<65$ years $(810$ prescriptions among those aged $0-11$ years and 1866 prescriptions among those aged 12-64 years).

Descriptive statistics were used to describe patients' and ICS characteristics, the days-supply-PER and the days-supply-Rx in sample 2 . We then calculated the concordance and $95 \%$ CI for the days' supply for all ICS combined and for specific ICS product and canister size, before and after applying the correction factors developed in sample 1 .

All analyses were performed using SAS V.9.3 (SAS Institute, Cary, North Carolina, USA).

\section{RESULTS}

For sample 1, we initially contacted 65 pharmacies by telephone, of which 10 refused to participate because of lack of time or staff, and 15 did not return the call. At the 40 pharmacies that participated in the study, we randomly selected 1216 ICS prescriptions, of which 108 (9\%) were excluded because the PER did not match the prescription, the dosage was not interpretable, or they included implausible values (see online supplementary material for more details). Among the prescriptions included in the analyses, $280(25 \%)$ were dispensed to those aged $0-11$ years and $828(75 \%)$ to those aged 12-64 years (table 1). The most frequently prescribed ICS was fluticasone in both age groups, while combination products were mostly prescribed to those aged those aged 12-64 years. The distributions of the days-supply-PER and the days-supply-Rx were different, but it is worth noting that for both variables the most frequent value was 30 days in both age groups. Of note, the duration of prescription written by the physician on the original prescription sheet was present for $42 \%$ of the prescriptions, and this duration did not correspond to the days-supply-Rx in $79 \%$ of cases (data not shown). The distributions of the refills-PER and the refills-Rx were comparable, in both age groups.

Concordance results for sample 1 are reported in table 2. The overall concordance between days-supplyPER and days-supply-Rx was $39.6 \%$ (95\% CI $37.6 \%$ to 
Table 1 Patients' characteristics, ICS prescribed, and distribution of days' supply and number of refills allowed of ICS recorded in the PER and on the original prescription $(\mathrm{Rx})$ in sample 1

\begin{tabular}{|c|c|c|c|c|}
\hline Characteristic & \multicolumn{2}{|l|}{ Age $0-11$ years } & \multicolumn{2}{|l|}{ Age 12-64 years } \\
\hline Male sex, $\mathrm{n}(\%)$ & \multicolumn{2}{|l|}{$168(60.0)$} & \multicolumn{2}{|l|}{$353(42.6)$} \\
\hline \multicolumn{5}{|l|}{ Insurance drug plan, n (\%) } \\
\hline Public & \multicolumn{2}{|l|}{$142(50.7)$} & \multicolumn{2}{|l|}{$410(49.5)$} \\
\hline Beclomethasone & \multicolumn{2}{|l|}{$12(4.3)$} & \multicolumn{2}{|l|}{$17(2.1)$} \\
\hline Budesonide & \multicolumn{2}{|l|}{$4(1.4)$} & \multicolumn{2}{|l|}{$86(10.4)$} \\
\hline Ciclesonide & \multicolumn{2}{|l|}{$19(6.8)$} & \multicolumn{2}{|l|}{$44(5.3)$} \\
\hline Fluticasone & \multicolumn{2}{|l|}{$231(82.5)$} & \multicolumn{2}{|l|}{$435(52.5)$} \\
\hline Budesonide/formoterol & \multicolumn{2}{|l|}{$4(1.4)$} & \multicolumn{2}{|l|}{135 (16.3) } \\
\hline$<15$ days & 38 (13.6) & $0(0.0)$ & $56(6.8)$ & $0(0.0)$ \\
\hline $15-29$ days & 47 (16.8) & $0(0.0)$ & $175(21.1)$ & $30(3.6)$ \\
\hline 30 days & $163(58.2)$ & $141(50.4)$ & $540(65.2)$ & $538(65.0)$ \\
\hline $31-59$ days & $1(0.3)$ & $7(2.5)$ & $11(1.3)$ & $74(8.9)$ \\
\hline 60 days & $26(9.3)$ & $115(41.1)$ & $34(4.1)$ & $149(18.0)$ \\
\hline$>60$ days & $5(1.8)$ & $17(6.0)$ & $12(1.5)$ & $37(4.5)$ \\
\hline Number of refills allowed & Refill-PER n (\%) & Refills-Rx n (\%) & Refill-PER n (\%) & Refills-Rx n (\%) \\
\hline 0 & $96(34.3)$ & $104(37.2)$ & $199(24.0)$ & $202(24.4)$ \\
\hline $1-3$ & $74(26.4)$ & 67 (23.9) & $120(14.5)$ & 123 (14.9) \\
\hline $4-10$ & 37 (13.2) & 40 (14.3) & $124(15.0)$ & $131(15.8)$ \\
\hline $11-90$ & $26(9.3)$ & $21(7.5)$ & 215 (26.0) & 199 (24.0) \\
\hline Code 99 & 47 (16.8) & 48 (17.1) & $170(20.5)$ & 173 (20.9) \\
\hline
\end{tabular}

$41.6 \%)$ in those aged $0-11$ years and $56 \%$ (95\% CI $54.9 \%$ to $57.2 \%$ ) in those aged $12-64$ years, but the concordance varied between 10.5 and $100 \%$ depending on the ICS product. The concordance between refills-PER and refills-Rx was $92.1 \%(95 \%$ CI $91 \%$ to $93.2 \%)$ in those aged $0-11$ years and $93.1 \%$ (95\% CI $92.5 \%$ to $93.7 \%$ ) in those aged $12-64$ years.

As the concordance for the number of refills allowed was excellent, we only developed correction factors for the days' supply. The correction factors were derived from the most frequent dosages and corresponding days' supply obtained from the original prescriptions (ie, days-supply-Rx) for each ICS product and canister size in sample 1 (see e-tables 1 and 2 for the distributions of days-supply-Rx and number of puffs per day). More specifically, the correction factors state that all values of the days-supply-PER that do not correspond to a dosage of two or four puffs per day will be corrected by the most frequent value of the days-supply-Rx observed in sample 1 for a specific product and canister size (see table 3 for the details of the correction factors). It is worth noting that dosages of two or four puffs per day corresponded to $97 \%$ of the ICS original prescriptions among those aged $0-11$ years and $96 \%$ among those aged $12-64$ years in sample 1 (percentages derived from e-tables 1 and 2 ). As seen in table 3 , the correction value for the days-supply-PER was the same in both age groups, except for beclomethasone (200 puffs), budesonide (200 puffs) and fluticasone/salmeterol (120 puffs).

As shown in table 2, the overall concordance for the days' supply after correction in sample 1 was $61.4 \%$ (95\% CI $59.4 \%$ to $63.4 \%)$ in those aged $0-11$ years and $81.2 \%$ (95\% CI $80.2 \%$ to $82.1 \%$ ) in those aged 12 64 years.

Descriptive characteristics for sample 2 are available in e-table 3. Again, fluticasone was the most prescribed ICS in both age groups. Also, the distribution of the days-supply-PER and the days-supply-Rx differed. The overall concordance between days-supply-PER and days-supply-Rx before and after applying the correction factors were $45.9 \%$ ( $44.7 \%$ to $47.1 \%$ ) and $59.4 \%$ (58.2\% to $60.5 \%$ ), respectively, in those aged $0-11$ years, while they were $52.7 \%(51.9 \%$ to $53.5 \%)$ and $74.2 \%$ (73.5\% to $74.9 \%$ ), respectively, in those aged $12-64$ years (table 4 ). 


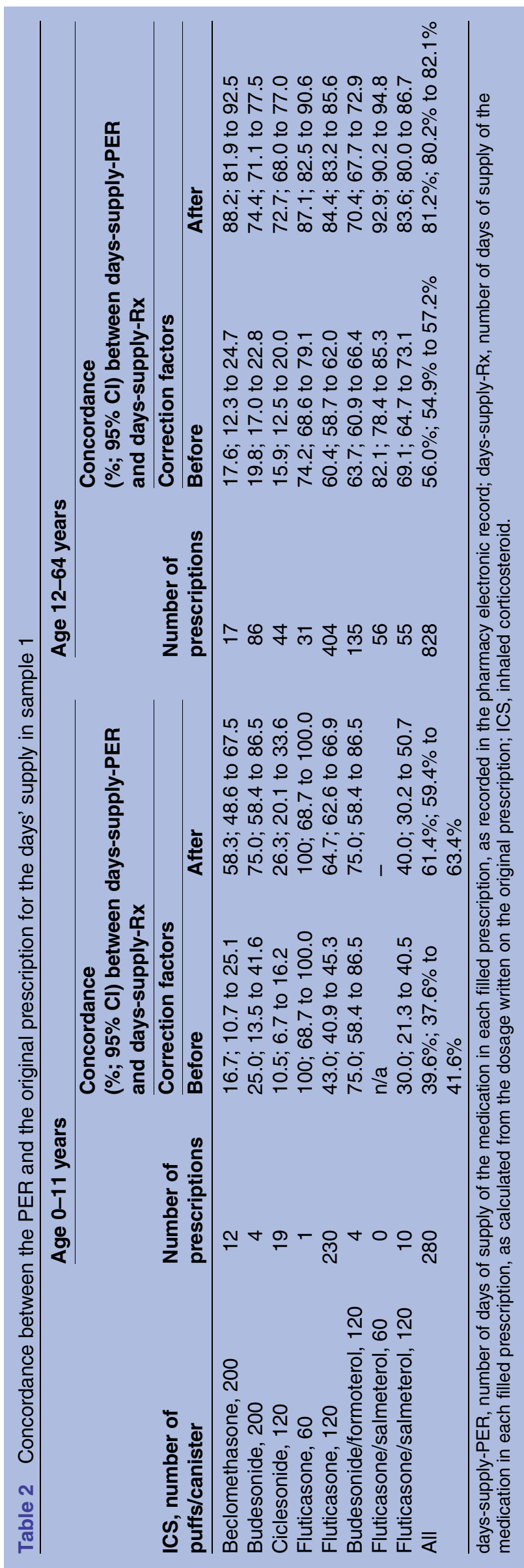

\section{DISCUSSION}

Our study found that the concordance of the days' supply of ICS between the PER (ie, days-supply-PER) and the original prescription (ie, days-supply-Rx) was fair in those aged $0-11$ years and moderate in those aged 12-64 years. However, after applying the proposed correction factors in the second sample, the concordance improved to $59.4 \%$ in those aged $0-11$ years and $74.2 \%$ in those aged $12-64$ years. We also found that the accuracy of the number of refills allowed was almost perfect $(>90 \%)$ in both age groups.

To our knowledge, the present study is the first to assess the accuracy of the number of refills allowed, while a few studies have evaluated the accuracy of the days' supply recorded in claims databases. The level of concordance for the days' supply for ICS was lower than the values of $70-96 \%$ that were previously reported for various medications at various dosage forms, ${ }^{12} 13$ 16-18 but was higher than that reported for respiratory medications. ${ }^{12}{ }^{13}$ Although Tamblyn et $a l^{16}$ did not specifically evaluate the concordance for respiratory drugs, Farris et $a l^{13}$ reported that the level of concordance was worst for inhalers because only 2/11 (18\%) prescriptions showed concordance between the original prescription and the claims database. The study by Gross et $a l^{18}$ involved patients receiving oral treatment for HIV, which might explain the high level of concordance. Finally, although the study by Jackevicius $e t a l^{12}$ involved a homogeneous patient population (post-myocardial infarction), it assessed the level of concordance for several types of medications, including respiratory medications for which the concordance was $34.6 \%$ based on 23 prescriptions. $^{12}$

Our study confirms that the concordance for the days' supply before applying the correction factors was low for ICS used to treat respiratory diseases. These medications are provided in canisters containing a fixed number of puffs, consequently the lifespan of the canister varies according to the prescribed number of puffs per day. In particular, the lower concordance in children than in adults might be explained by the fact that children are more likely to be prescribed low ICS doses, which means the lifespan may exceed the usual 30 days' supply. The lower concordance for ICS prescriptions may also be explained by the fact that pharmacists face a dilemma with these medications, as the days' supply field in the PER could be recorded as the number of days of treatment written on the original prescription (eg, 10 days) or the number of days the canister will last if the patient takes the ICS at the prescribed dosage. This dilemma possibly exists because the day's supply in the PER may be viewed by the pharmacist as a field lacking importance as it is not used on the prescription label. We also cannot exclude the possibility that some physicians might prescribe ICS for less than 15 days to treat an asthma exacerbation or for an indication other than asthma. In addition, prescriptions with directions that include 'as needed' may be problematic and lead to 
Table 3 Correction factors for the days-supply-PER for ICS prescriptions derived from sample 1

\begin{tabular}{|c|c|c|}
\hline \multirow{2}{*}{$\begin{array}{l}\text { ICS product, number of } \\
\text { puffs/canister }\end{array}$} & \multicolumn{2}{|c|}{ Correction factors for the days-supply-PER } \\
\hline & Age 0-11 years & Age 12-64 years \\
\hline Beclomethasone, 200 & $\begin{array}{l}\text { Replace all values by } 100 \text { days, } \\
\text { except for } 50 \text { and } 100 \text { days }\end{array}$ & $\begin{array}{l}\text { Replace all values by } 50 \text { days, } \\
\text { except for } 50 \text { and } 100 \text { days }\end{array}$ \\
\hline Budesonide, 200 & $\begin{array}{l}\text { Replace all values by } 100 \text { days, } \\
\text { except for } 50 \text { and } 100 \text { days }\end{array}$ & $\begin{array}{l}\text { Replace all values by } 50 \text { days, } \\
\text { except for } 50 \text { and } 100 \text { days }\end{array}$ \\
\hline Ciclesonide, 120 & $\begin{array}{l}\text { Replace all values by } 60 \text { days, } \\
\text { except } 30 \text { and } 60\end{array}$ & $\begin{array}{l}\text { Replace all values by } 60 \text { days, } \\
\text { except } 30 \text { and } 60\end{array}$ \\
\hline Fluticasone, 60 & $\mathrm{n} / \mathrm{a}$ & $\begin{array}{l}\text { Replace all values by } 30 \text { days, } \\
\text { except } 15 \text { and } 30\end{array}$ \\
\hline Fluticasone, 120 & $\begin{array}{l}\text { Replace all values by } 30 \text { days, } \\
\text { except } 30 \text { and } 60\end{array}$ & $\begin{array}{l}\text { Replace all values by } 30 \text { days, } \\
\text { except } 30 \text { and } 60\end{array}$ \\
\hline Budesonide/formoterol, 120 & $\begin{array}{l}\text { Replace all values by } 30 \text { days, } \\
\text { except } 30 \text { and } 60\end{array}$ & $\begin{array}{l}\text { Replace all values by } 30 \text { days, } \\
\text { except } 30 \text { and } 60\end{array}$ \\
\hline Fluticasone/salmeterol, 60 & $\mathrm{n} / \mathrm{a}$ & $\begin{array}{l}\text { Replace all values by } 30 \text { days, } \\
\text { except } 15 \text { and } 30\end{array}$ \\
\hline Fluticasone/salmeterol, 120 & $\begin{array}{l}\text { Replace all values by } 60 \text { days, } \\
\text { except } 30 \text { and } 60\end{array}$ & $\begin{array}{l}\text { Replace all values by } 30 \text { days, } \\
\text { except } 30 \text { and } 60\end{array}$ \\
\hline
\end{tabular}

variable interpretations of the days' supply to be recorded (eg, 4 puffs/day, with a maximum of 8 puffs/ day as needed).

We also observed that the level of concordance for the days' supply varied according to the ICS product and the canister size, and it was very low before correction for beclomethasone 200 puffs, budesonide 200 puffs and ciclesonide 120 puffs. These ICS are generally prescribed in dosages such that the canister will last for more than 30 days, and we believe that in these cases, pharmacists

Table 4 Concordance between the days-supply-PER and the days-supply-Rx in sample 2

\begin{tabular}{|c|c|c|c|c|c|c|}
\hline \multirow{3}{*}{$\begin{array}{l}\text { ICS, number of } \\
\text { puffs/canister }\end{array}$} & \multicolumn{3}{|l|}{ Age $0-11$ years } & \multicolumn{3}{|c|}{ Age $12-64$ years } \\
\hline & \multirow{2}{*}{$\begin{array}{l}\text { Number of } \\
\text { prescriptions }\end{array}$} & \multicolumn{2}{|c|}{$\begin{array}{l}\text { Concordance (\%; } 95 \mathrm{Cl}) \\
\text { Correction factors }\end{array}$} & \multirow{2}{*}{$\begin{array}{l}\text { Number of } \\
\text { prescriptions }\end{array}$} & \multicolumn{2}{|c|}{$\begin{array}{l}\text { Concordance (\%; } 95 \mathrm{Cl}) \\
\text { Correction factors }\end{array}$} \\
\hline & & Before & After & & Before & After \\
\hline $\begin{array}{l}\text { Beclomethasone, } \\
200\end{array}$ & 43 & $34.9 ; 30.2$ to 39.9 & $51.2 ; 46.0$ to 52.3 & 11 & $18.2 ; 11.7$ to 27.2 & $81.8 ; 72.8$ to 88.3 \\
\hline Budesonide, 200 & 7 & $42.9 ; 31.1$ to 55.5 & $57.1 ; 44.5$ to 68.9 & 235 & $21.3 ; 19.5$ to 23.1 & $60.0 ; 57.8$ to 62.1 \\
\hline Ciclesonide, 120 & 149 & $36.9 ; 34.3$ to 39.6 & $40.3 ; 37.6$ to 43.0 & 114 & $28.1 ; 25.3$ to 31.0 & $75.4 ; 72.6$ to 78.1 \\
\hline Fluticasone, 60 & 2 & $\begin{array}{l}100.0 ; 81.5 \text { to } \\
100.0\end{array}$ & $\begin{array}{l}100.0 ; 81.5 \text { to } \\
100.0\end{array}$ & 72 & $70.8 ; 67.1$ to 74.3 & $80.6 ; 77.2$ to 83.5 \\
\hline Fluticasone, 120 & 583 & $48.4 ; 47.0$ to 49.8 & $63.8 ; 62.5$ to 65.1 & 900 & $53.3 ; 52.2$ to 54.5 & $77.9 ; 76.9$ to 78.8 \\
\hline Mometasone, 30* & 0 & - & - & 8 & $\begin{array}{l}100.0 ; 94.6 \text { to } \\
100.0\end{array}$ & $\begin{array}{l}100.0 ; 94.6 \text { to } \\
100.0\end{array}$ \\
\hline Mometasone, $60^{\star}$ & 0 & - & - & 2 & $50.0 ; 28.5$ to 71.5 & $50.0 ; 28.5$ to 71.5 \\
\hline $\begin{array}{l}\text { Budesonide/ } \\
\text { formoterol, } 120\end{array}$ & 5 & $60.0 ; 45.0$ to 73.3 & $60.0 ; 45.0$ to 73.3 & 306 & $57.8 ; 55.9$ to 59.7 & $59.1 ; 57.2$ to 61.0 \\
\hline $\begin{array}{l}\text { Fluticasone/ } \\
\text { salmeterol, } 60\end{array}$ & 1 & $\begin{array}{l}100.0 ; 68.7 \text { to } \\
100.0\end{array}$ & $\begin{array}{l}100.0 ; 68.7 \text { to } \\
100.0\end{array}$ & 114 & $89.5 ; 87.4$ to 91.3 & $95.6 ; 94.1$ to 96.7 \\
\hline $\begin{array}{l}\text { Fluticasone/ } \\
\text { salmeterol, } 120\end{array}$ & 20 & $55.0 ; 47.5$ to 62.3 & $60.0 ; 52.5$ to 67.1 & 92 & $78.3 ; 75.2$ to 81.0 & $89.1 ; 86.7$ to 91.1 \\
\hline $\begin{array}{l}\text { Mometasone/ } \\
\text { formoterol, } 120^{*}\end{array}$ & 0 & - & - & 12 & $75.0 ; 65.8$ to 82.4 & $75.0 ; 65.8$ to 82.4 \\
\hline All & 810 & $\begin{array}{l}45.9 \% ; 44.7 \% \text { to } \\
47.1 \%\end{array}$ & $\begin{array}{l}59.4 \% ; 58.2 \% \text { to } \\
60.5 \%\end{array}$ & 1866 & $\begin{array}{l}52.7 \% ; 51.9 \% \text { to } \\
53.5 \%\end{array}$ & $\begin{array}{l}74.2 \% ; 73.5 \% \text { to } \\
74.9 \%\end{array}$ \\
\hline
\end{tabular}

${ }^{*}$ No correction factor developed for these three drugs in sample 1.

days-supply-PER, number of days of supply of the medication in each filled prescription, as recorded in the pharmacy electronic record; days-supply-Rx, number of days of supply of the medication in each filled prescription, as calculated from the dosage written on the original prescription; ICS, inhaled corticosteroid. 
tended to record 30 days' supply instead of the exact days' supply. One possible reason behind that is the fact that some private insurance companies limit the days' supply to 30 days, which might not be suitable for ICS prescriptions. After applying the correction factors, the concordance improved significantly for these three ICS products.

Our validation study has several strengths, including the use of a representative large population-based sample of ICS prescriptions covering patients up to 65 years of age, the possibility to develop and validate correction factors for the days' supply in an independent second large sample, and being the first study to assess the accuracy of the number of refills allowed. In the field of pharmacoepidemiology, it is important that the days' supply recorded in prescription claims databases be valid because we assess medication adherence by summing the days' supply of all prescriptions filled during the study period, and this serves as a proxy of the number of days the patient took the medication. As such, the days' supply is more important than the duration of the prescription written by the physician on the original prescription sheet.

This study has also limitations that need to be mentioned. In particular, we did not include patients aged $>65$ years, as the reMed database does not include them. This might reduce the external validity of our study, if prescription patterns of ICS differ with age. The post hoc age stratification (ie, $0-11$ and 12-64 years) based on ICS drug monographs reduced the number of patients in the younger group. Finally, the clinical indication for the ICS prescriptions was unknown, and probably the accuracy of the days' supply for ICS would have been better if only asthmatic patients were considered.

In summary, we found that the information recorded in Québec prescription claims databases used to calculate adherence measures was accurate but only after correction. By focusing on ICS in this study, we probably explored a worst-case scenario, and it is likely that the accuracy would have been better with tablets. Conflicting possible interpretations of the days' supply for ICS limit the accuracy as currently recorded. We recommend that the pharmacists be given clearer instructions regarding what should be recorded for days-supply-PER, namely, the duration (number of days) of the ICS inhaler at the prescribed dosage be recorded, taking into consideration the maximum number of puffs per day when the dosage is variable. In addition, if the number of days of treatment stated on the original prescription does not correspond to the days' supply, we recommend that it be recorded in a new field in the PER. The observed inaccuracies in the days' supply may have had an impact (likely underestimation) on measures of adherence calculated in our previous studies (eg, the proportion of days covered and the proportion of prescribed days covered). ${ }^{5}{ }^{10}$ In future studies, we plan to formally compare those measures of adherence assessed over 1 year, before and after applying the proposed correction factors in a cohort of new ICS users selected from Québec's prescriptions claims databases.

\section{Author affiliations}

${ }^{1}$ Faculté de Pharmacie, Université de Montréal, Montréal, Québec, Canada

${ }^{2}$ Hôpital du Sacré-Cœur de Montréal, Montréal, Québec, Canada

${ }^{3}$ Endowment Pharmaceutical Chair AstraZeneca in Respiratory Health,

Montréal, Québec, Canada

${ }^{4}$ Pharmacy Department, Centre Hospitalier Universitaire de Sherbrooke,

Sherbrooke, Québec, Canada

${ }^{5}$ Centre de Recherche Clinique Étienne-Le Bel, Centre Hospitalier Universitaire de Sherbrooke, Sherbrooke, Québec, Canada

${ }^{6}$ Clinical Research and Knowledge Transfer Unit on Childhood Asthma,

Research Centre, CHU Sainte-Justine, Montréal, Canada

${ }^{7}$ Department of Pediatrics, University of Montréal, Montréal, Québec, Canada.

Acknowledgements The authors would like to thank all pharmacists/ technicians who participated to the present study.

Contributors LB conceived the research project with M-FB, FMD and CL. GL and $A V$ collected the data. AF helped with the analysis of data and statistics. F-ZK helped with the review of literature and the preparation of the first draft of the manuscript. All the authors revised and approved the final version of the manuscript.

Funding This work was supported by the Conseil du Médicament/Fonds de Recherche du Québec-Santé (FRQS).

Competing interests LB received research grants from AstraZeneca, Genentech, Pfizer, Sanofi-Aventis, Merck and Novartis between 2010 and 2013. M-FB received a research grant from GSK Canada for the conduct of a research project (investigator initiated). LB and M-FB co-chair the AstraZeneca Research Chair in Respiratory Health. FMD received research funds and fees for speaking from Novartis, Takeda (formally Nycomed) and Merck Frosst Inc, received consultancy fee from Boehringer Ingelheim, and served on an advisory board for Novartis. In the past 3 years, CL has seated on the advisory boards of AstraZeneca, GlaxoSmithKline and Merck. CL has also acted as a consultant for AstraZeneca and GlaxoSmithKline and she has provided continuing medical education sponsored by Merck and AstraZeneca. $\mathrm{AF}, \mathrm{GL}, \mathrm{FZK}$ and $\mathrm{AV}$ have no conflicts of interests to declare.

Ethics approval This study was approved by the Ethics Committee of Hôpital du Sacré-Coeur de Montréal and CHU Sainte-Justine.

Provenance and peer review Not commissioned; externally peer reviewed.

Data sharing statement No addition data are available.

Open Access This is an Open Access article distributed in accordance with the Creative Commons Attribution Non Commercial (CC BY-NC 4.0) license, which permits others to distribute, remix, adapt, build upon this work noncommercially, and license their derivative works on different terms, provided the original work is properly cited and the use is non-commercial. See: http:// creativecommons.org/licenses/by-nc/4.0/

\section{REFERENCES}

1. Jones C, Santanello NC, Boccuzzi SJ, et al. Adherence to prescribed treatment for asthma: evidence from pharmacy benefits data. J Asthma 2003;40:93-101.

2. Williams LK, Pladevall M, Xi H, et al. Relationship between adherence to inhaled corticosteroids and poor outcomes among adults with asthma. J Allergy Clin Immunol 2004;114:1288-93.

3. Marceau C, Lemiere C, Berbiche D, et al. Persistence, adherence, and effectiveness of combination therapy among adult patients with asthma. J Allergy Clin Immunol 2006;118:574-81.

4. Delea TE, Stanford RH, Hagiwara M, et al. Association between adherence with fixed dose combination fluticasone propionate/ salmeterol on asthma outcomes and costs*. Curr Med Res Opin 2008;24:3435-42.

5. Pando S, Lemiere C, Beauchesne MF, et al. Suboptimal use of inhaled corticosteroids in children with persistent asthma: inadequate prescription, poor drug adherence, or both? Pharmacotherapy 2010;30:1109-16. 
6. Perreault S, Dragomir A, Blais L, et al. Impact of better adherence to statin agents in the primary prevention of coronary artery disease. Eur J Clin Pharmacol 2009;65:1013-24.

7. Dragomir A, Cote R, Roy L, et al. Impact of adherence to antihypertensive agents on clinical outcomes and hospitalization costs. Med Care 2010;48:418-25.

8. Andrade SE, Kahler $\mathrm{KH}$, Frech $\mathrm{F}$, et al. Methods for evaluation of medication adherence and persistence using automated databases. Pharmacoepidemiol Drug Saf 2006;15:565-74.

9. Hess LM, Raebel MA, Conner DA, et al. Measurement of adherence in pharmacy administrative databases: a proposal for standard definitions and preferred measures. Ann Pharmacother 2006:40:1280-8.

10. Blais L, Kettani FZ, Beauchesne MF, et al. New measure of adherence adjusted for prescription patterns: the case of adults with asthma treated with inhaled corticosteroid monotherapy. Ann Pharmacother 2011;45:335-41.

11. Ivanova JI, Birnbaum HG, Hsieh M, et al. Adherence to inhaled corticosteroid use and local adverse events in persistent asthma. Am J Manag Care 2008;14:801-9.

12. Jackevicius CA, Paterson JM, Naglie G. Concordance between discharge prescriptions and insurance claims in post-myocardial infarction patients. Pharmacoepidemiol Drug Saf 2007;16:207-15.

13. Farris KB, Kaplan B, Kirking DM. Examination of days supply in computerized prescription claims. J Pharmacoepidemol 1994:3:63-76.

14. Landis JR, Koch GG. An application of hierarchical kappa-type statistics in the assessment of majority agreement among multiple observers. Biometrics 1977;33:363-74.

15. Lougheed MD, Lemiere C, Dell SD, et al. Canadian Thoracic Society Asthma Management Continuum-2010 Consensus Summary for children six years of age and over, and adults. Can Respir $J$ 2010;17:15-24.

16. Tamblyn R, Lavoie G, Petrella L, et al. The use of prescription claims databases in pharmacoepidemiological research: the accuracy and comprehensiveness of the prescription claims database in Quebec. J Clin Epidemiol 1995;48:999-1009.

17. Kozyrskyj AL, Mustard CA. Validation of an electronic, population-based prescription database. Ann Pharmacother 1998;32:1152-7.

18. Gross R, Bilker WB, Strom BL, et al. Validity and comparison of two measures of days supply in Medicaid claims data. Pharmacoepidemiol Drug Saf 2008;17:1029-32. 